\title{
Analysis of Energy Management in Micro-grid with Distributed Generation System
}

\author{
Jegedeesh Kumar Rajagopal $^{1}$, Vignesh Thangavel $^{2}$ \\ ${ }^{1}$ Department of Electrical and Electronics Engineering, Karpagam College of Engineering, Coimbatore, India \\ ${ }^{2}$ SVS Equipments Corporation, Coimbatore, India
}

Email address:

jegadeeshkumar.eee@gmail.com(J. K. Rajagopal),vigneshstar104@gmail.com (V. Thangavel)

To cite this article:

Jegedeesh Kumar Rajagopal, Vignesh Thangavel. Analysis of Energy Management in Micro-grid with Distributed Generation System. American Journal of Modern Energy. Vol. 6, No. 6, 2020, pp. 117-123. doi: 10.11648/j.ajme.20200606.12

Received: July 20, 2020; Accepted: August 3, 2020; Published: December 16, 2020

\begin{abstract}
The Energy management in Micro-Grid system is one of the most irrefutable issues in micro grid technology development. The Micro grid energy system consists on non-conventional resources, unit with storage energy and islanded or grid connected mode of operating loads. This tabloid presents a Micro-Grid energy management system for distributed generation connected MG with hybrid energy storage system. Hybrid energy storage system is achieved by combining the Ultra-capacitor and battery storage. The proposed energy management system in micro grid with hybrid energy storage system follows the two techniques, such as forecasting and optimization. Prediction of solar irradiance, load demand and temperature are coming under the Forecasting technique. For the economical operation in a grid connected micro grid the optimal dayahead scheduling of power generation and load demand is performed by the optimization technique. The MG will absorb or deliver the prespecified amount of power. In this method MG connected to the power grid in large numbers are integrated. The main intension of the energy management system is power balancing in the micro grid. The MATLAB/Simulink environment has been used to analyzing the effect of Energy management in micro-gird with hybrid energy storage system. The simulation results will show the effective and stoutness of the proposed energy management method.
\end{abstract}

Keywords: Energy Management, Micro-grid, Distributed Generation, Battery and Ultra-capacitor

\section{Introduction}

Diesel generators are the major power supply to the remote societies. Cost of the diesel is comparatively very expansive and unfavorable to the atmosphere hence it is results in great burden to the local economy. The only one alternative solution for the isolated micro grid is renewable source. In growing renewable energy technology and the minimum operational cost, the photovoltaic energy source is better than the other renewable sources. Due to the intermittency and uncertainty characteristics on non-conventional source energy fails to withstand the reliability of the standalone power supply. To overcome these characteristics issues in renewable sources the battery backup and other energy storage systems are added to the MG [1]. Thus, the distribution generation application has gained impetus. The implementation of distribution generations to the utility grid provides the additional advantages to the micro grid concept [2]. The micro grid is coming under the small-scale power grid, and consists of an association of DG's and loads [3]. Micro grids follow the two different types of operation methods. Such as non-autonomous method and another one is autonomous method. In autonomous method the utility grid power is not exchanged with the MG and is operated in islanded mode. In non-autonomous method the utility grid power is exchanged with MG [4]. The bus voltage value is declared by utility grid in non-autonomous method meanwhile the bus voltage value in autonomous method is depends upon the subsystem of DG. In both function modes of the system to maintain the seamless operation and algorithm for efficient control to the power balance, taking into account the both modes of power grid operation characteristics are required [5].

The inefficient power exchange determines the operation mode's advantages. Hence renewable sources in large numbers are prevented hence it requires different energy management techniques. As the renewable sources are results unpredictable in nature then the storage element is necessary to maintain the efficient power exchange. In renewable energy source energy management system, the popularly 
used storage device is battery [6]-[7]. It plays a vital role in islanded mode to maintain the grid stability and power balance [8]. Energy storage in ultra-capacitor is in the form of an electric field, Instead of in chemical reactions such as batteries. The charging and discharging are faster than the batteries due to the high-power density in ultra-capacitor. Smooth the flow of power and load shifting can be done by storage devices [9]. The main intention of this tabloid is increasing the micro-grid DC's depth of penetration. For this purpose, an efficient method of energy management is considered for a DC micro-grid, for a preset amount of power to be absorbed or delivered by the micro grid. Hybrid ultracapacitor /battery energy storage system is considered in Energy management system $[10,11]$. In wide variety of dynamic system, the modeling and simulating is carried out by Simulink interactional milieu. The blocks are used to build the system easily and display the results quickly. Scrutinize possessions of non-linearity of the micro grid power system is done by Simulink and therefore it is a perfect research environment tool. The usage of Simulink is budding hastily in research effort in the domain of electrical power system and also in the other domains. Simulink is used to develop the model of DC micro-grid with hybrid energy storing system and the examination of energy management system is discussed in this paper.

\section{System Description}

Figure 1 Shows the layout of DC micro-grid with renewable energy system and it consists of the following components,

1. It is $400 \mathrm{~V}$ DC bus micro-grid. Power electronic

$$
H_{o}=\frac{24}{\pi} s\left(1+0.033 \cos \frac{360 n}{365}\right)\left(\omega_{s} \sin \emptyset \sin \delta+\cos \emptyset \cos \delta \sin \omega_{s}\right)
$$

Where $\mathrm{S}$ is the constant of solar, $\mathrm{n}$ is the day of a year, $\omega_{s}$ is the sunrise hour angle for horizontal collector, latitude of the location is given by $\emptyset$ and the declination is given by $\delta$.

Conduct the effective power flow the Hybrid Energy converter (PEC) is used to connect all the subsystem into the micro-grid.

2. To conduct the load transfer and power flow even the storage system is used. Battery and ultra-capacitor forms the hybrid energy storage system.

3. AC load is interfaced with Power electronic converter. Voltage source converter is acts as a current source. Utility grid and micro-grid is connected through the PEC. Photovoltaic (PV) panel is connected with microgrid by VSC.

The output power of the PV panel $P_{p v}$ is given by,

$$
\mathrm{P}_{\mathrm{PV}}=\mathrm{V}_{\mathrm{PV}} \times \mathrm{I}_{\mathrm{PV}}
$$

Where,

$\mathrm{V}_{\mathrm{pv}}$ - Output voltage of PV panel,

$\mathrm{I}_{\mathrm{pv}}$ - Output current of PV panel,

Similarly,

$$
\begin{gathered}
\mathrm{P}_{\mathrm{bat}}=\mathrm{V}_{\mathrm{bat}} \times \mathrm{I}_{\mathrm{bat}} \\
\mathrm{P}_{\mathrm{uc}}=\mathrm{V}_{\mathrm{uc}} \times \mathrm{I}_{\mathrm{uc}}
\end{gathered}
$$

The eqn (2) gives the output power of the Battery $P_{b a t}$. $V_{b a t}$ is battery output voltage and $I_{b a t}$ is battery output current. The enq (3) gives the output power of the ultracapacitor $P_{u c} . V_{u c}$ is output voltage of ultra-capacitor and $I_{b a t}$ is output current of ultra-capacitor. The power consumed by the AC loads is given by $P_{l}$ and the amount of power exchanged with utility grid is $P_{u}$. The extra-terrestrial solar radiation $H_{o}$ is given in the eqn (4).

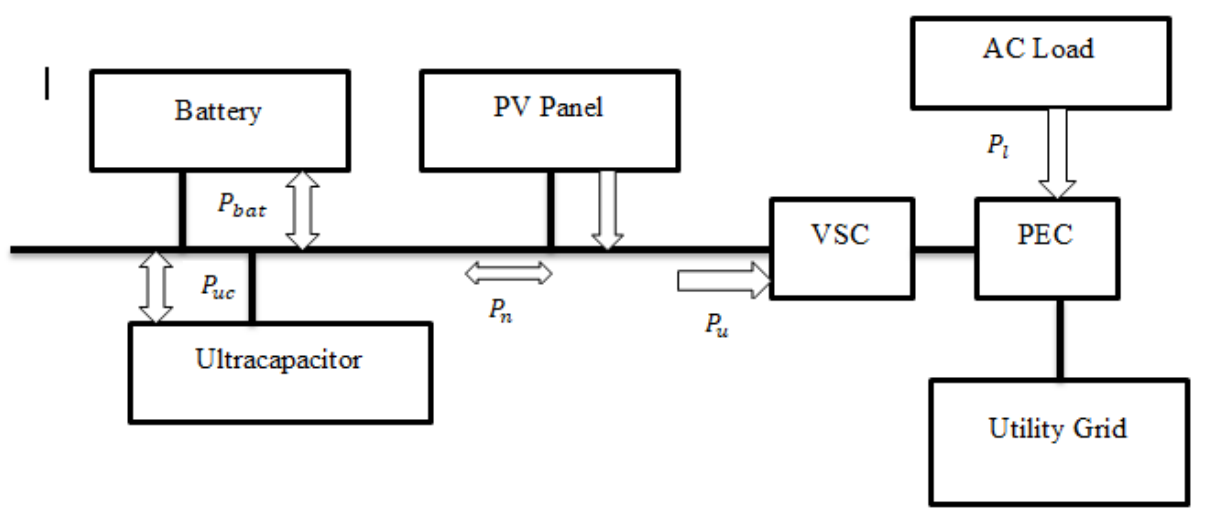

Figure 1. DC micro-grid system layout.

DC micro-grid occupies only small area and span of the transmission line very short and hence the impedance of line will be lesser.
Storage System consists of battery and ultra-capacitor, because one type of component with limited capacity energy storage system is not enough to conduct the varying power.

will be lesser.

\section{Operation Method}

Similar the non-conventional method, based on the operational strategy in the work ultra-capacitor is used as dc 
link back up without altering to autonomous and nonautonomous mode. Then the operational strategy will be more flexible and reliable. Throughout non-autonomous mode, the PV panel operates under Maximum Power Point Tracking (MPPT) mode and the PEC is kept in ON state and dc link is supported by the ultra-capacitor. Power flow will be conducted by hybrid energy storage system, where the power exchanged with the utility gird is prespecified quantity by the VSC. Where VSC acts like current source. Through Autonomous mode, PEC is kept ON state, the PV panel follows Maximum Power Point Tracking mode and it output power is harvested. Still ultra-capacitor is used as dc link back up. Power flow only through the hybrid energy storage system and no power will flow through the VSC and the PEC. In both autonomous and non-autonomous modes the VSC is controlled hence during operation mode problem by switching will be avoided. For both modes it requires a single energy management method. Also throughout both operation modes renewable source, hybrid energy storage system and VSC control theories will remain same.

The power exchange amid the micro-grid and utility grid cannot be determined in traditional designs which creates more complicates in power transferring. In the proposed method the prespecified amount of power will be exchanged with the utility grid by the VSC control. Hence the simplified power transferring will be achieved.

Figure 1 displays the micro-grid layout, which consists of photovoltaic panel, energy storage and utility grid interfaced AC loads. Power system controls provide the ON or OFF signals to the utility grid. The layout advantages are the system cost can be reduced and prespecified power transfer amid the micro-grid and utility grid is attainable. Increase the integration of non-conventional sources into the utility grid the better method is micro-grid technology. The quantity of power to be compensated $\left(P_{\text {com }}\right)$ given in the eqn $(5)$.

$$
\mathrm{P}_{\text {com }}=\mathrm{P}_{\mathrm{PV}}-\mathrm{P}_{\text {load }}
$$

Figure 1 mentions that $P_{\text {com }}$ 's average value is $P_{u}$, which is the predetermined quantity of power to be transferred amid micro-grid and utility grid.

\section{Method of Energy Management}

Based on the power flow the energy management is designed and the VSC controls the PEC switching action. During autonomous mode the AC voltage phase angle, frequency will be maintained by VSC and during nonautonomous mode DC voltage will be maintained by the VSC. PV panel produced power is $P_{p v}$. Power absorbed by the various loads is $P_{l}$, the power to be exchanged with the utility grid is $P_{u}$. The net power $P_{n}$ flow in the micro grid is given as

$$
\mathrm{P}_{\mathrm{n}}=\mathrm{P}_{\mathrm{PV}}-\mathrm{P}_{\mathrm{l}}-\mathrm{P}_{\mathrm{u}}
$$

The net power $P_{n}$ of the micro-grid effectively conducted by hybrid energy storage system. Owing to the occasional nature of the non-conventional source and the several loads changing its performance then the net power of micro-grid
$P_{n}$ changing continuously. Main aim of the energy management technology is to the accomplish the power balance. Both ultra-capacitor and battery SOC (State of Charge) will be determined by the corresponding terminal voltage at that instant. Therefore SOC can be written as...

$$
\text { SOC } \alpha V_{t}
$$

Where, $V_{t}$ is micro-grid battery and ultra-capacitor's terminal voltage. In energy management system minimum and maximum SOC level are predetermined voltage values and which are used as the two limit points.

Figure 2 displays the energy management algorithm flowchart. In the energy management technique, primarily the ultracapacitor and battery state were fixed as 0 value and the SOC minimum and maximum value of the battery and ultra-capacitor are well-defined. The difference amid load power and PV power is called reference power. If the reference power value is positive then it is checked. Then the ultra-capacitor's and battery's state of charge will be checked with its corresponding minimum reference value. The value is within the range then the ultra-capacitor and battery will proceeds to discharge. Else if the reference power value is negative value then the ultracapacitor's and battery's state of charge will be rechecked with its corresponding maximum reference value. If the reference value is less than the maximum reference value then ultracapacitor and battery will proceeds to charge. According to the reference value the battery and ultra-capacitor will discharge or charge. Therefore control of net power flow and energy management has been achieved and hence power balance is also attained. To avoid the deep charging or over charging SOC's minimum and maximum values are defined for the ultracapacitor and battery. Energy management will control the discharging or charging of hybrid energy storage system and power condition in the micro-grid.

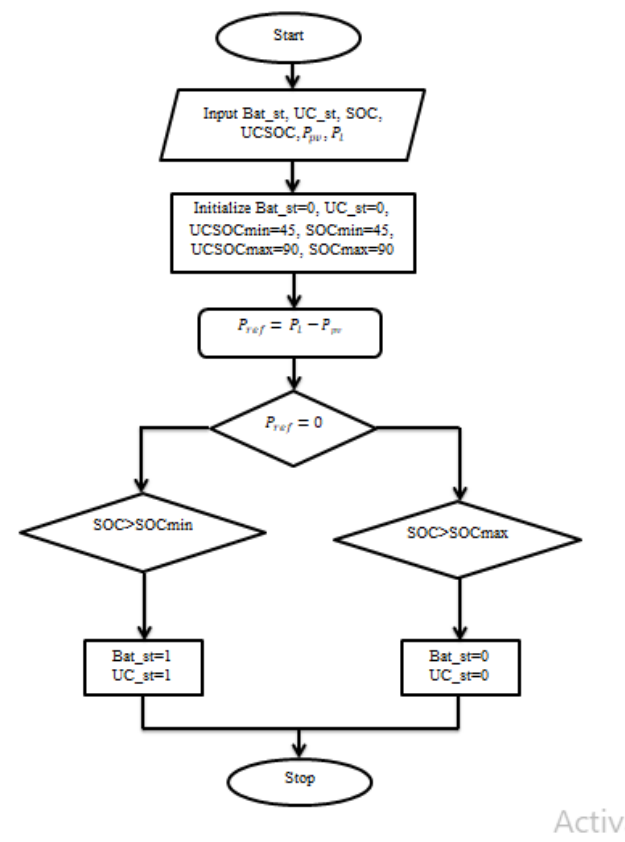

Figure 2. Flowchart of Energy Management. 


\section{Subsystem Component Control}

\subsection{Renewable Source Control}

Connect the PV panel to the DC bus the dc-dc boost converter is used. PV panel operates under MPPT mode and the maximum power received from it. MPP tracking follows Perturb and Observe algorithm in this control.

\subsection{The VSC Control}

VSC (Voltage Source Controller) behave as a current source throughout the both non-autonomous and autonomous mode.

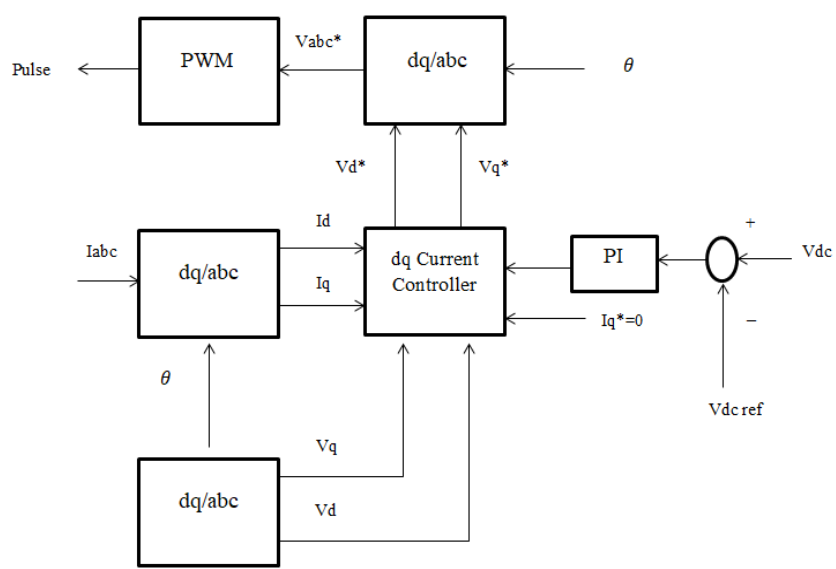

Figure 3. Control Scheme of VSC.

The Figure 3 displays the VSC control scheme, where DQZ transformation is used. To rotate the $\mathrm{AC}$ waveforms reference frames can be done by the transform so that they become DC signals. To find out the phase angle of grid voltage the PLL has been used. The Clarke transform is used in DQZ transformation to convert $\mathrm{ABC}$ referenced vectors into two differential mode components. The $\mathrm{D}$ (direct) component transformed as X component, which is in direct alignment with the rotation vector, and $\mathrm{Q}$ component transformed as $\mathrm{Y}$ component, it is direct component's angle of quadrature. Throughout the non-autonomous mode, the reference of direct current is from the central controller and reference of quadrature current will be equal to zero. Throughout the autonomous mode the two references are zero.

\section{Simulation Model}

Hybrid Energy Storage System micro-grid with distributed generation system is developed by MATLAB/Simulink Software. $500 \mathrm{~V}$ DC is considered as base dc link voltage. $100 \mathrm{~kW}$ PV array is connected through the Boost converter to the DC bus. The Boost converter follows the Perturb and Observe algorithm. Battery with capacity of $24 \mathrm{~V} / 100 \mathrm{Ah}$, ten in quantity is used. Ultra-capacitor with capacity of 54V/100 $\mathrm{F}$ which are five in number are used. Batteries and Ultracapacitors are connected through the bi-directional dc-dc converter to the DC bus. VSC is connected amid DC bus and Utility grid. $45 \mathrm{~kW}$ AC load is connected to the line. Figure 4 displays the Hybrid Energy Storage System micro-grid with distributed generation system MATLAB/Simulink model. 3 phase circuit breaker is placed amid load and utility grid. Energy management achieved in both non-autonomous and autonomous mode. Maximum irradiance of the model is $1000 \mathrm{~W} / \mathrm{m}^{2}$ and the constant temperature 25 degree celcius. There is decerement in input irradiance hence the storage energy and grid energy is shared to the load. The calculation made in this system are PV Array power, Demand Power, Battery Power and Ultra-capacitor Power and SOC of both Battry and Ultra-capacitor. Terminal Voltage of the DC line is taken as reference and adjustment made on it.

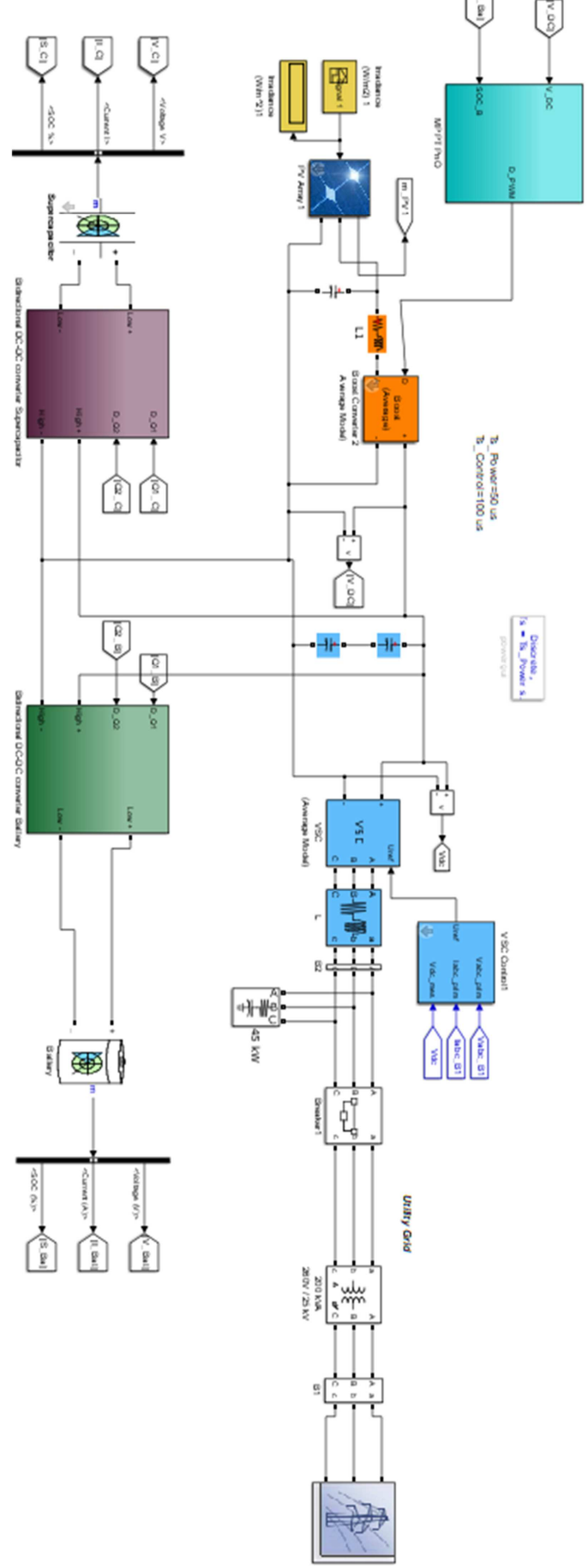

Figure 4. Micro-grid MATLAB Model. 


\section{Simulation Results}

\subsection{Autonomous Mode}

In this mode Simulation conducted for 0.5 seconds, where varying irradiation level and constant temperature. From $\mathrm{t}=0$ sec the irradiance level is $1000 \mathrm{~W} / \mathrm{m}^{2}$ to $\mathrm{t}=0.25 \mathrm{sec}$ where the $\mathrm{PV}$ output power is nearly $70 \mathrm{~kW}$. At this time AC load draws the power. Battery and Ultra-capacitor charge and discharge. From $\mathrm{t}=0.25 \mathrm{sec}$ to $\mathrm{t}=0.35 \mathrm{sec}$ the irradiance value decreased to $500 \mathrm{~W} / \mathrm{m}^{2}$ where the $\mathrm{PV}$ output power is also decreased to
40kW. Remaining load power is shared by Battery and Ultracapacitor. From $\mathrm{t}=0.35 \mathrm{sec}$ to $\mathrm{t}=0.5 \mathrm{sec}$ the irradiance value increased to $1000 \mathrm{~W} / \mathrm{m}^{2}$ where the output power of PV array is nearly $70 \mathrm{~kW}$. Figure $5 \mathrm{a}$ displays the AC load power of the system. Figure $5 \mathrm{~b}$ displays the irradiance value. Figure $5 \mathrm{c}$ displays the PV output power. Figure 5d shows the Battery SOC and Figure 5e shows the Battery power. Figure $5 \mathrm{f}$ shows the Ultra-capacitor SOC and Figure $5 \mathrm{~g}$ shows the Ultra-capacitor power.

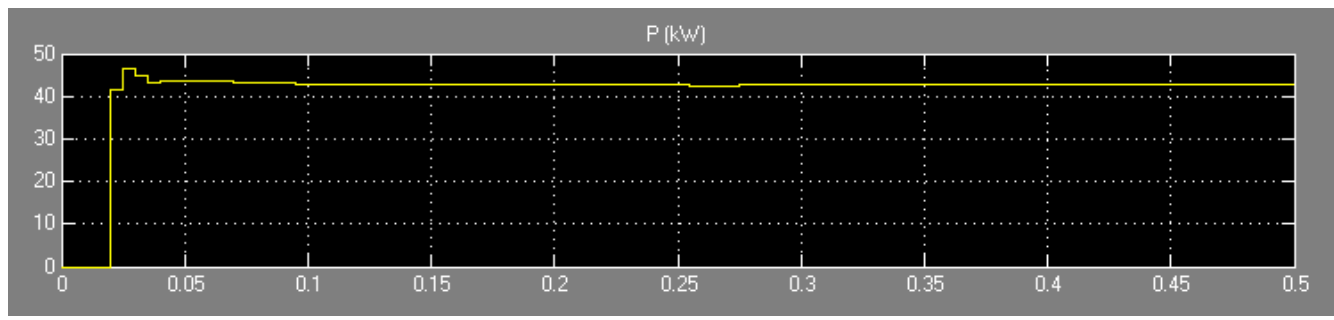

(a)

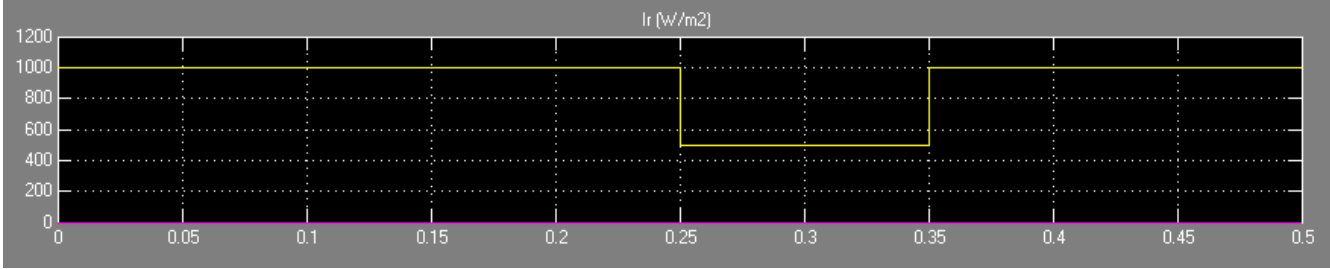

(b)

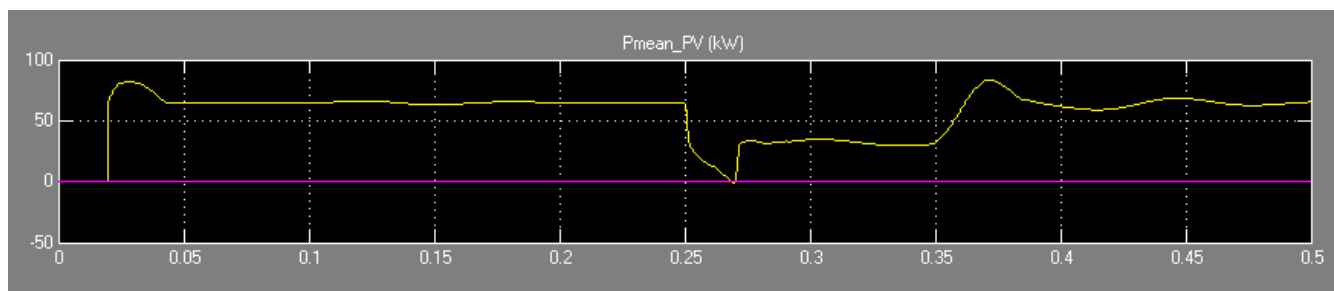

(c)

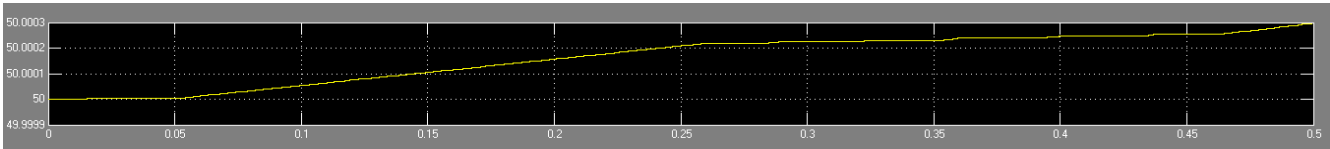

(d)

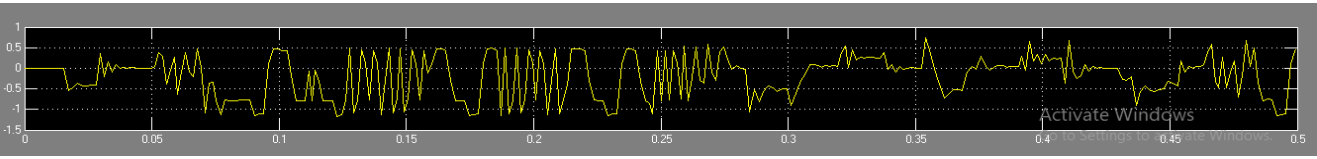

(e)

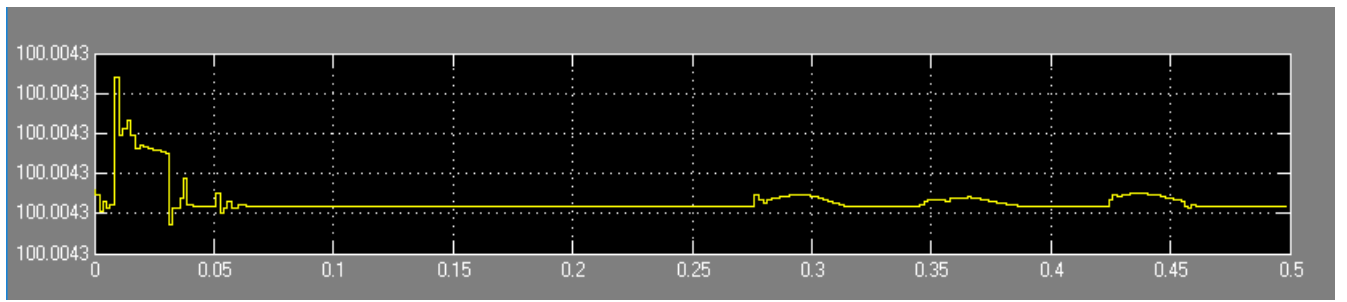

(f) 


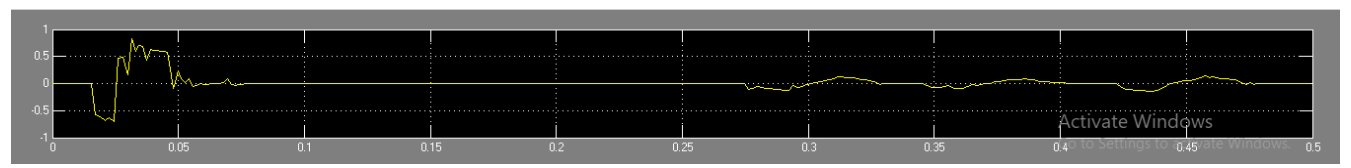

(g)

Figure 5. (a) AC Load power; (b) Irradiance Level; (c) PV output power; (d) Battery SOC; (e) Battery Output Power; (f) Ultra-capacitor SOC; (g) Ultracapacitor Output Power.

\subsection{Non-Autonomous Mode}

In this mode Simulation conducted for 0.5 seconds, where varying irradiation level and constant temperature. From $\mathrm{t}=0$ $\mathrm{sec}$ the irradiance level is $1000 \mathrm{~W} / \mathrm{m}^{2}$ to $\mathrm{t}=0.25 \mathrm{sec}$ where the $\mathrm{PV}$ output power is nearly $70 \mathrm{~kW}$. At this time AC load draws the power. Battery and Ultra-capacitor charge and discharge. Remaining power will be transmitted to the utility grid. From $\mathrm{t}=0.25 \mathrm{sec}$ to $\mathrm{t}=0.35 \mathrm{sec}$ the irradiance value decreased to 500 $\mathrm{W} / \mathrm{m}^{2}$ where the PV output power is also decreased to $40 \mathrm{~kW}$. Remaining load power is shared by Battery and Ultracapacitor but this is not enough to maintain the stability in the system hence utility grid power is drawn to maintain the stability. From $\mathrm{t}=0.35 \mathrm{sec}$ to $\mathrm{t}=0.5 \mathrm{sec}$ the irradiance value increased to $1000 \mathrm{~W} / \mathrm{m}^{2}$ where the output power of PV array is nearly $70 \mathrm{~kW}$. Battery and Ultra-capacitor charge and discharge. Remaining power will be transmitted to the utility grid. Figure 6 a displays the AC load power of the system. Figure $6 \mathrm{~b}$ displays the irradiance value. Figure $6 \mathrm{c}$ displays the PV output power. Figure 6d shows the Battery SOC and Figure 6e shows the Battery power. Figure 6f shows the Ultra-capacitor SOC and Figure $6 \mathrm{~g}$ show the Ultra-capacitor power. Figure $6 \mathrm{~g}$ displays the grid power transmission.

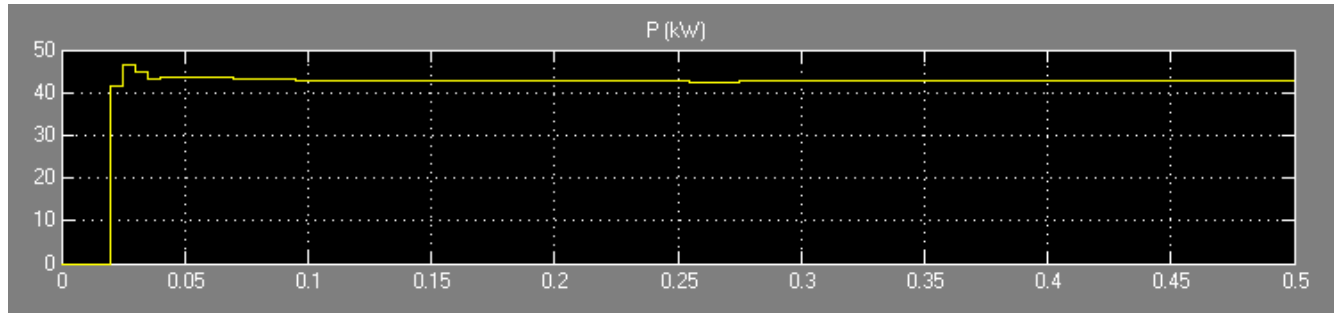

(a)

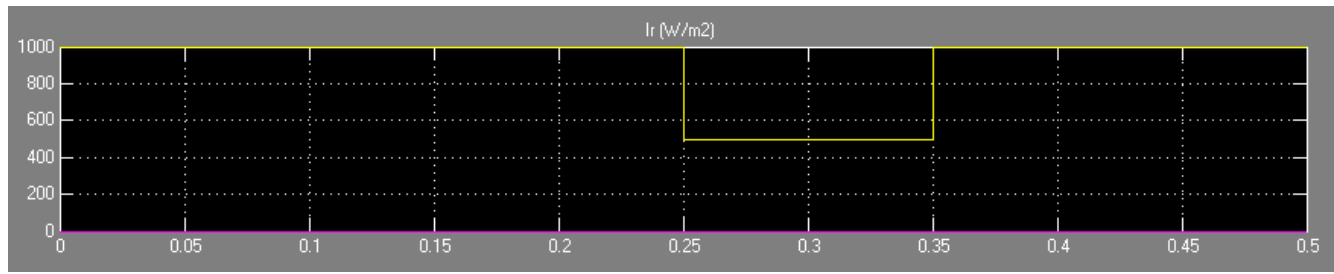

(b)

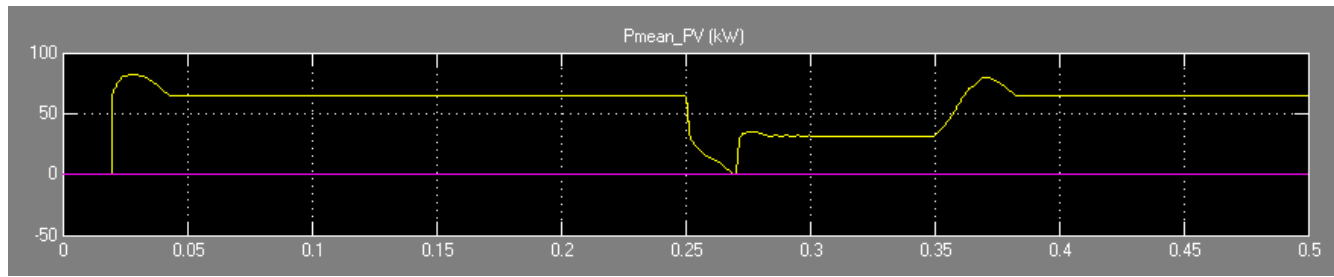

(c)

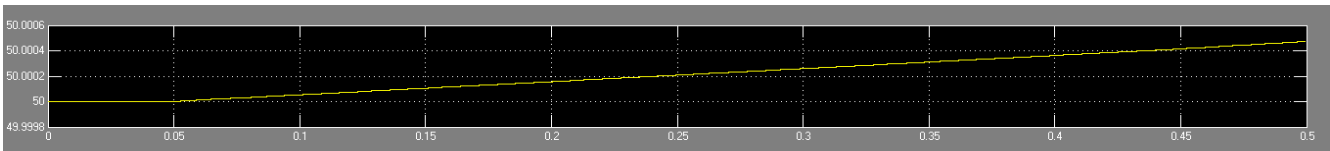

(d)

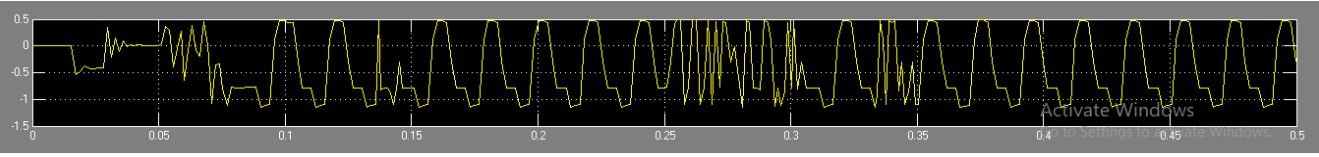

(e) 


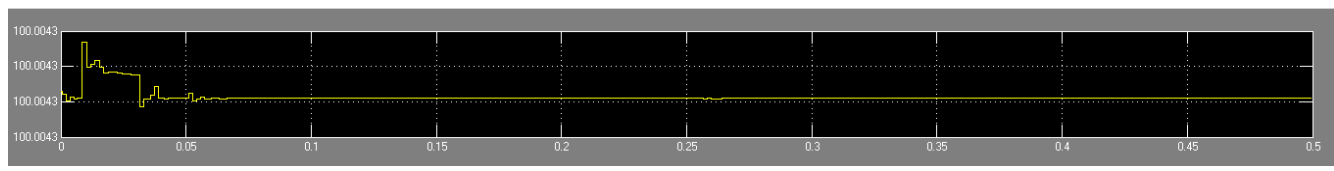

(f)

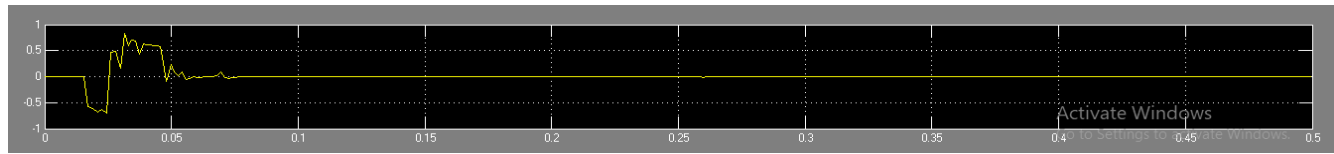

(g)

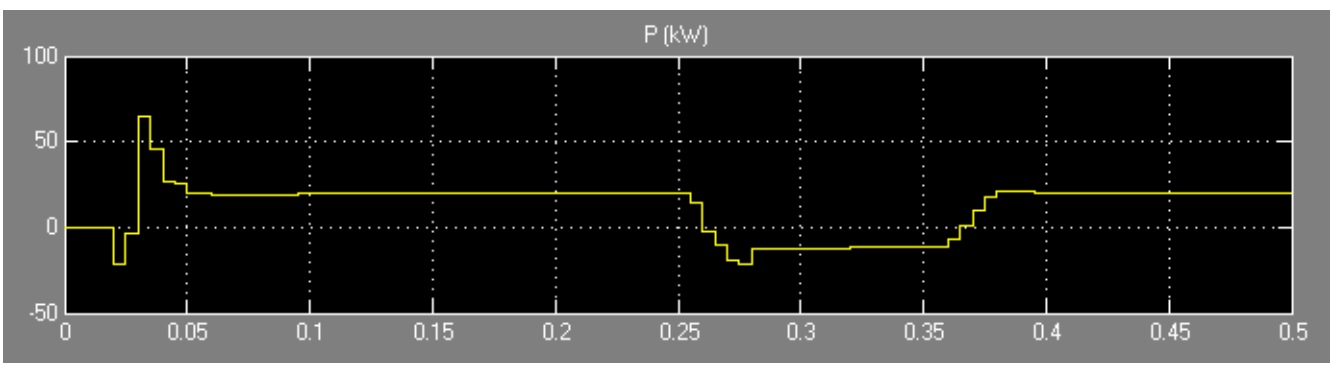

(h)

Figure 6. (a) AC Load power; (b) Irradiance Level; (c) PV output power; (d) Battery SOC; (e) Battery Output Power; (f) Ultra-capacitor SOC; (g) Ultracapacitor Output Power; (h) Utility grid Power.

\section{Conclusion}

In this tabloid the Energy management in hybrid energy storage system micro-gird with distributed generation is studied during both autonomous and non-autonomous mode. The powers delivered by PV array and storage system and utility grid are calculated. Power exchange amid micro-grid and utility grid is calculated in this paper. MATLAB/Simulink simulation environment is used to perform the examination of Energy Management method.

\section{References}

[1] F. Katiraei, M. R. Iravani, and P. W. Lehn, "Micro-grid autonomous operation during and subsequent to islanding process," IEEE Trans. Power Del, vol. 22, no. 1, pp. 248-257, Jan 2005 .

[2] U. B. Tayab, M. A. B. Roslan, L. J. Hwai, and M. Kashif, "A review of droop control techniques for microgrid," Renewable and Sustainable Energy Reviews, vol. 76, pp. 717-727, 2017.

[3] S. F. Rafique and Z. Jianhua, "Energy management system, generation and demand predictors: a review," IET Generation, Transmission \& Distribution, vol. 12, no. 3, pp. 519-530, 2018.

[4] A. C. Luna, N. L. Diaz, M. Graells, J. C. Vasquez, and J. M. Guerrero, "Generation and demand scheduling for a gridconnected hybrid microgrid considering price-based incentives," in IECON 2017 - 43rd Annual Conference of the IEEE Industrial Electronics Society, 2017, pp. 2498-2503.
[5] A. Baliyan, K. Gaurav, and S. K. Mishra, "A Review of Short Term Load Forecasting using Artificial Neural Network Models," Procedia Computer Science, vol. 48, pp. 121-125, 2015.

[6] R. Sathishkumar, S. K. Kollimala and M. K. Mishra, "Dynamic energy management of microgrids using battery supercapacitor combined storage," in IEEE India Conf, Kochi, India, 2012.

[7] J. Zhang et al., "A Bi-Level Program for the Planning of an Islanded Microgrid Including CAES," IEEE Trans. Ind. Appl., vol. 52, no. 4, pp. 2768-2777, 2016.

[8] Usman Bashir Tayab, Fuwen Yang, Mohamed El-Hendawi and Junwei Lu, "Energy Management System for a GridConnected Microgrid with Photovoltaic and Battery Energy Storage System", in Australian \& New Zealand Control Conference, Australia, Dec - 2018.

[9] R. Dufo-López and J. L. Bernal-Agustín, "Multi-objective design of PVwind-diesel-hydrogen-battery systems," Renew. Energy, vol. 33, no. 12, pp. 2559-2572, 200.

[10] N. Eghtedarpour and E. Farjah, "Distributed charge / discharge control of energy storages in a renewable energy based DC micro-grid," IET Renew. Power Gener, vol. 8, no. 1, pp. 45-57, Jan 2014.

[11] Sreelekshmi R S, Prasad A and M. G Nair, "Control and Operation of micro-grid connected Hybrid Energy Storage System," in International Conference on Energy Efficient Technologies for Sustainability 2016, 2016. 